\title{
Building and Application of Cardiopulmonary Bypass Model in
}

\section{Rats}

\author{
Kun Zhang ${ }^{1}$, Rui Xue ${ }^{2^{*}}$ and Shuwei Shen ${ }^{1}$ \\ ${ }^{1}$ Department of Anesthesiology, Jingzhou Central Hospital,The Second Clinical Medical College, Yangtze University, \\ Jingzhou, Hubei Province,434020, China. \\ ${ }^{2}$ Department of Anesthesiology, Renmin Hospital, Hubei University of Medicine, shiyan,Hubei, China. \\ *Corresponding author: 7885909@qq.com
}

\begin{abstract}
To build a cardiopulmonary bypass model in rats, and research the feasibility. Method Cardiopulmonary bypass was built in 10 adult male SD rats of clean grade through intubation in jugular vein, caudal artery, and femoral artery, and bypass was sustained for $60 \mathrm{~min}$ at the flow rate of $100 \mathrm{ml} /(\mathrm{kg} \cdot \mathrm{min})$ to monitor heart rate, blood pressure, blood gas, and electrolyte. Result Puncture succeeded in all the 20 rats, and cardiopulmonary bypass was finished under given conditions. Conclusion The model has the following advantages, economical efficiency, simplicity, minimal invasion, cardiopulmonary bypass parameter setting similar to that of clinical trail, high rate of success. Thus, it is reliable for researching pathological and physiological changes after cardiopulmonary bypass and evaluating therapeutic strategy.
\end{abstract}

Keywords: Rat, anesthesia, cardiopulmonary bypass, building.

\section{Experimental material and method}

\subsection{Material}

10 healthy adult male SD rats of clean grade, body mass: $350 \sim 500 \mathrm{~g},(424 \pm 70)$ on average. Inhibited from drinking water within $6 \mathrm{~h}$ before operation.

\subsection{Test Equipment}

Cardiopulmonary bypass rolling blood pump, with silicon pump with an internal diameter of 4mm; membrane oxygenator specially used for rats (surface area: $0.10 \mathrm{~m}^{2}$ ), ECG monitor; blood-gas analyzer and heat exchanger; temperature changing water bank [1].

\subsection{Anesthesia and Monitor}

A peritoneal injection of $0.2 \%$ pentobarbital sodium solution according to the standard of $50 \mathrm{mg} / \mathrm{kg}$ was given to rats for anesthesia, and then rats were fixed on rat fix table, monitored with an ECG monitor, and tested for rectal temperature.

The body temperature of rats were sustained around $35.5 \sim 36.0^{\circ} \mathrm{C}$ with a temperature changing water bank [2]. A blood-gas analyzer was employed to test and analyze arterial blood gas, electrolyte, mixed venous oxygen saturation, and 
lactate levels. Tests were carried out before systemic circulation, 30min after systemic circulation, upon systemic circulation being finished, and $30 \mathrm{~min}$ after the finish of systemic circulation.

\section{Building of cardiopulmonary bypass}

(1)The skin of left groin was cut about $0.8 \mathrm{~cm}$; left femoral artery was separated and ligated, a $24 \mathrm{G}$ venous indwelling needle was stabbed through proximal end of ligation for fixation, and heparin solution was injected (half of $500 \mathrm{U} / \mathrm{kg}$ ), a monitor was connected via a transducer for continuous monitoring arterial blood pressure. Specimens can be taken via this bypass [3].

(2) The middle of on proximal end ventral side of cauda was cut about $0.8 \mathrm{~cm}$; a $20 \mathrm{G}$ venous indwelling needle was stabbed in the same way for femoral artery for arterial perfusion.

(3) The $16 \mathrm{G}$ venous indwelling needle clipped so that its frond end had multiple lateral pores, and the front end of the steel core was smoothened so as to avoid any injury to vessel wall at the time of puncture. The right neck was cut lengthways about $1 \mathrm{~cm}$ for separating external jugular vein, of which the distal end was ligated, and the abovementioned venous indwelling needle was stabbed into the proximal end, so that the tip of puncture needle was close to the entrance of postcava of right atrium to serve as venous drainage tube.

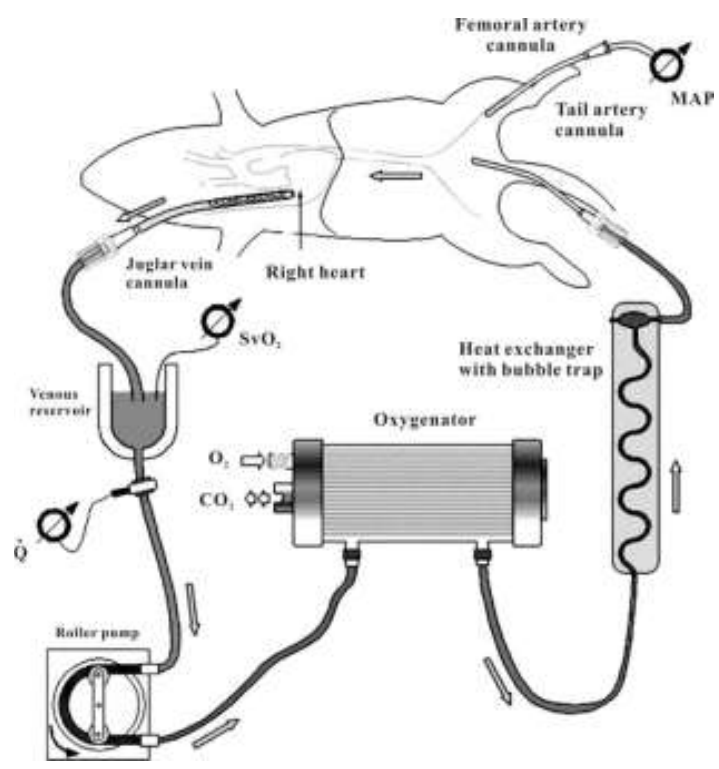

Cardiopulmonary Bypass Model

\section{Result}

Intubation tube and cardiopulmonary bypass in all rats succeeded. Please see Tab. 1 for haemodynamics and blood gas analysis and body temperatures before and after cardiopulmonary bypass. During bypass, the blood pressure of rats can be manually controlled via adjusting drainage and perfusion. The monitoring of blood pressure showed that early blood pressure during and after bypass was lower than that before bypass $(\mathrm{P}<0.05)$. Blood gas analysis showed that arterial partial pressure of oxygen and partial pressure of carbon dioxide roughly remained in the normal ranges. An acidosis trend was showed with the progress of bypass. 
Tab. 1 Analysis and Comparison of Haemodynamics, Temperature and Blood Gas Before and After Cardiopulmonary Bypass ( $\bar{x} \pm \mathrm{s})$

\begin{tabular}{|c|c|c|c|c|c|c|c|}
\hline $\begin{array}{c}\text { Before cardiopulmonary } \\
\text { bypass }\end{array}$ & $105.7 \pm 4.9$ & $310.5 \pm 19.3$ & $36.8 \pm 0.4$ & $133.1 \pm 13.7$ & $41.9 \pm 1.1$ & $7.41 \pm 0.03$ & $45.4 \pm 3.2$ \\
\hline $\begin{array}{l}\text { 30min after } \\
\text { cardiopulmonary bypass }\end{array}$ & $75.9 \pm 9.8^{*}$ & $232.7 \pm 23.5^{*}$ & $29.4 \pm 0.7^{*}$ & $267.8 \pm 15.4^{*}$ & $36.9 \pm 0.9^{*}$ & $7.38 \pm 0.04^{*}$ & $30.6 \pm 2.8^{*}$ \\
\hline $\begin{array}{l}\text { Upon the end of } \\
\text { cardiopulmonary bypass }\end{array}$ & $92.5 \pm 6.3^{*}$ & $307.5 \pm 19.9$ & $37.2 \pm 0.5^{*}$ & $289.9 \pm 15.3^{*}$ & $39.2 \pm 1.3^{*}$ & $7.33 \pm 0.04^{*}$ & $28.7 \pm 1.6^{*}$ \\
\hline
\end{tabular}

*P $<0.05$ between the four groups.

\section{Discussion}

The cardiopulmonary bypass model in rats we built has the following advantages, economical efficiency, simplicity, minimal invasion, cardiopulmonary bypass parameter setting similar to that of clinical trail, high rate of success, long duration, etc. Through preliminary studies, we found that these conditions would injure liver and kidney of rats to a certain extent, so can used for researching organ injury after cardiopulmonary bypass. Comparing with previous experimental models, reduction of trauma caused by factors other than cardiopulmonary bypass was emphasized in this model. Firstly, this model needs no thoracotomy, so that the integrity of thorax was maintained, sternum was not cut, and inflammatory response was reduced $[4,5,6,7]$. Secondly, autonomous respirations were retained, tracheal intubation or thracheotomy were not conducted for mechanical assisted ventilation. This is also significantly different from cases reported before. Since satisfactory anesthetic effect can be achieved through intraperitoneal injection of pentobarbital sodium, rats had no response to pain stimulation, operation had not significantly influenced blood pressure and heart rate, and no respiratory depression occurred. That these invasive manipulations were avoided is an important reason that the survival rate of out rats was high; besides, that thoracotomy or mechanical assisted ventilation that impact the body were not carried out will create conditions for researches to purely analyze the pathological physiological changes caused by cardiopulmonary bypass.

Comparing with cardiopulmonary bypass building via thoracotomy, the operation of cardiopulmonary bypass building via peripheral vessel intubation is simpler, because intubation is relatively easier. Besides, the latter is physiologically same with the former, but the thorax remains stable in the latter operation, good for the recovery of respiratory function after operation. Thus, in recent years, the cases of building of cardiopulmonary bypass in rats without thoracotomy were reported. The main intubation way is reverse perfusion through caudal artery. Blood flow varies with physiological conditions, and it is not suitable for cerebral perfusion. Therefore, we adopted internal carotid artery perfusion based on overseas experience, which conforms to the physiological conditions $[8,9,10,11,12]$. In most cases reported in China, cardiopulmonary bypass was realized under normal temperature, while DHLF and DHCA are needed for simulating physiological states in researches on cerebal protection. Thus, building DHLF or DHCA without thoracotomy is particularly important. Building cardiopulmonary bypass via peripheral vessel intubation can be used for 
researches on cardiopulmonary bypass of different types, such as CPB, DHLF, DHCA, etc. This experiment also verified this. Cardiopulmonary bypass in all rats succeeded, their vital signs, physical and chemical indicators during CPB remained in the acceptable ranges, and the rats all successfully got over cardiopulmonary bypass after the end of experiment. On this basis, I have reason to regard this model as a reliable platform for research on physiology of cardiopulmonary bypass.

CPB model in rats can be used for research on physiopathologic mechanism of system inflammatory response and organ function changes caused by $\mathrm{CPB}$, and facilitates further discussions on strategy of organ protection in clinical perioperative period, worth further study and exploration.

\section{References}

1. Selnes OA, Goldsborough MA, Borowicz LM and Mckhann GM. Neurobehavioural sequelae of cardiopulmonary bypass. Lancet. (1999) 353: 1601-1606.

2. Joshi B, Brady K, Lee J, Easley B, Panigrahi R,Smielewski P, Czosnyka M and Hogue CW. Impaired autoregulation of cerebral blood flow during rewarming from hypothermic cardiopulmonary bypass and its potential association with stroke. Anesth Analg.(2010) 110: 321-328

3. Jeleazcov C, Saari TI, Ihmsen H, Schuttler J and Fechner J. Changes in total and unbound concentrations of sufentanil during target controlled infusion for cardiac surgery with cardiopulmonary bypass. Br. J.Anaesth. (2012) 109: 698-706.

4. Ranucci M, Isgrò G, Carlucci C, Torre T, Enginoli S and Frigiola A. Central venous oxygen saturation and blood lactate levels during cardiopulmonary bypass are associated with outcome after pediatric cardiac surgery. Crit. Care. (2010) 14: 1-10.

5. Townend WJ, Guy MJ, Pani MA, Martin B and Yates DW. Head injury outcome prediction in the emergency department: a role for protein S-100B? J. Neurol.Neurosurg. Psychiatry (2002) 73: 542-546.

6. Acharya UR, Joseph KP, Kannathal N, Lim CM and Suri JS. Heart rate variability: a review. Med. Bio. Eng.Comput. (2006) 44: 1031-1051

7. Wang Z, Leng Y, Tsai L-K, Leeds P and Chuang D-M.Valproic acid attenuates blood-brain barrier disruption in a rat model of transient focal cerebral ischemia: the roles of HDAC and MMP-9 inhibition. J. Cereb. Blood Flow. Metab. (2011) 31: 52-57.

8. Wolfler A, Salvo I, Sortino G, Bonati F and Izzo F.Epidural analgesia with ropivacaine and sufentanil is associated with transient fetal heart rate changes.Minerva. anestesiologica. (2010) 76: 340.

9. Li XM, Yang JM, Hu DH, Hou FQ, Zhao M, Zhu XH,Wang Y, Li JG, Hu P, Chen L, Qin LN and Gao TM.Contribution of downregulation of L-type calcium currents to delayed neuronal death in rat hippocampus after global cerebral ischemia and reperfusion. J.Neurosci. (2007) 27: 5249-5259.

10. Ranucci M, Isgrò G, Carlucci C, Torre T, Enginoli S and Frigiola A. Central venous oxygen saturation and blood lactate levels during cardiopulmonary bypass are associated with outcome after pediatric cardiac surgery. Crit. Care. (2010) 14: 1-10.

11. Arrowsmith JE, Grocott HP, Reves JG and Newman MF. Central nervous system complications of cardiac surgery. Br. J. Anaesth. (2000) 84: 378-393.

12. Schoknecht $\mathrm{K}$ and Shalev H. Blood-brain barrier dysfunction in brain diseases. Clin. Exper. Epileps.(2012) 53: 7-13. 